\title{
Molecular Orientation of a Terbium(III)-Phthalocyaninato Double-Decker Complex for Effective Suppression of Quantum Tunneling of the Magnetization
}

\author{
Tsutomu Yamabayashi ${ }^{1}$, Keiichi Katoh ${ }^{1, *}$, Brian K. Breedlove ${ }^{1}$ and Masahiro Yamashita ${ }^{1,2,3, *}$ \\ 1 Department of Chemistry, Graduate School of Science, Tohoku University, 6-3, Aramaki-Aza-Aoba, Aoba-ku, \\ Sendai, Miyagi 980-8578, Japan; tsutomu.yamabayashi.p3@dc.tohoku.ac.jp (T.Y.); \\ breedlove@m.tohoku.ac.jp (B.K.B.) \\ 2 WPI Research Center, Advanced Institute for Materials Research, Tohoku University, 2-1-1 Katahira, \\ Aoba-ku, Sendai 980-8577, Japan \\ 3 School of Materials Science and Engineering, Nankai University, Tianjin 300350, China \\ * Correspondence: kkatoh@m.tohoku.ac.jp (K.K.); yamasita.m@gmail.com (M.Y.)
}

Academic Editors: João Paulo C. Tomé, Michael Hanack and Augusto C. Tomé

Received: 28 April 2017; Accepted: 12 June 2017; Published: 15 June 2017

\begin{abstract}
Single-molecule magnet (SMM) properties of crystals of a terbium(III)-phthalocyaninato double-decker complex with different molecular packings (1: $\mathrm{TbPc}_{2}, 2$ : $\mathrm{TbPc}_{2} \cdot \mathrm{CH}_{2} \mathrm{Cl}_{2}$ ) were studied to elucidate the relationship between the molecular packing and SMM properties. From single crystal X-ray analyses, the high symmetry of the coordination environment of $\mathbf{2}$ suggested that the SMM properties were improved. Furthermore, the shorter intermolecular $\mathrm{Tb}-\mathrm{Tb}$ distance and relative collinear alignment of the magnetic dipole in $\mathbf{2}$ indicated that the magnetic dipole-dipole interactions were stronger than those in $\mathbf{1}$. This was confirmed by using direct current magnetic measurements. From alternating current magnetic measurements, the activation energy for spin reversal for $\mathbf{1}$ and $\mathbf{2}$ were similar. However, the relaxation time for $\mathbf{2}$ is three orders of magnitude slower than that for $\mathbf{1}$ in the low- $T$ region due to effective suppression of the quantum tunneling of the magnetization. These results suggest that the $\mathrm{SMM}$ properties of $\mathrm{TbPc}_{2}$ highly depend on the molecular packing.
\end{abstract}

Keywords: single-molecule magnets; terbium(III)-phthalocyaninato double-decker complex; quantum tunneling of magnetization; magnetic dipole-dipole interaction

\section{Introduction}

Single-molecule magnets (SMMs) have interesting quantum properties, such as slow magnetic relaxation [1,2] and quantum tunneling of magnetization (QTM) [3-5]. Since the discovery of the $\mathrm{Mn}_{12}$ cluster, several compounds showing slow magnetic relaxation have been reported. Lanthanoid(III) $\left(\mathrm{Ln}{ }^{\mathrm{III}}\right)$ complexes have been extensively studied because $\mathrm{Ln}^{\mathrm{III}}$ ions have a ground state multiplet with large angular momenta, $J=L+S$, and ligand field (LF) splitting of the ground state gives a large activation energy for spin reversal $\left(U_{\text {eff }}\right)$ compared to polynuclear complexes of transition metal ions [6-9].

One of the most promising classes of Ln SMMs is a family of bisphthalocyaninato complexes $\left(\mathrm{LnPc}_{2}\right)$ [8-16], which were shown to be SMMs in 2003 [8]. The electronic structure of $\mathrm{LnPc}_{2}$ has been reported by Ishikawa and co-workers [10]. The ground state of the $\mathrm{Tb}^{\mathrm{III}}$ ions, ${ }^{7} F_{6}$, which is caused by Russell-Saunders coupling, is mainly split by the strong axial LF around the $\mathrm{Tb}^{\mathrm{III}}$ ion. As a result, there is an energy gap between the ground states with $J_{\mathrm{Z}}= \pm 6$ and the first excited states with $J_{\mathrm{Z}}= \pm 5$ of $\sim 400 \mathrm{~cm}^{-1}$, which is attributed to $U_{\text {eff. }}$. Due to such a large $U_{\text {eff }}, \mathrm{TbPc}_{2}$ shows slow magnetic relaxation 
up to $\sim 50 \mathrm{~K}$, far surpassing transition metal SMMs, like the $\mathrm{Mn}_{12}$ cluster $(\sim 4 \mathrm{~K})$. In addition to the high $U_{\text {eff }}$ value, the high chemical stability and flat shape of the Pc ligands of TbPc $\mathrm{C}_{2}$ molecule enable it to be exploited in spintronics devices, such as spin transistors [17], spin valves [18,19] and spin quantum bits [20]. In those applications, quantum phenomena, such as QTM, are used to manipulate the spin states. For example, in the research on spin transistors, $\mathrm{TbPc}_{2}$ molecules have been inserted between gold electrodes, and addressing and detecting single nuclear spin states of the $\mathrm{Tb}$ ion have been demonstrated by using QTM events, which cause an abrupt jump in the differential conductance, $\mathrm{d} I / \mathrm{d} V$ [17].

On the other hand, nobody has prepared a quantum memory device based on $\mathrm{TbPc}_{2}$ since $\mathrm{TbPc}_{2}$ shows magnetic hysteresis only below $2 \mathrm{~K}$ despite the large $U_{\text {eff }}$ value $[10,11,21]$. This is mainly due to QTM, which takes place at random between the energetically matched levels on the opposite sides of the barrier. In 2013, Sessoli et al. reported that the magnetic hysteresis of $\mathrm{TbPc}_{2}$ depended on the environment of the crystalline phase [21]. They report that a thermally treated amorphous sample does not show magnetic hysteresis even at $2 \mathrm{~K}$, whereas a pristine crystalline sample shows clear hysteresis at the same temperature. The disappearance of the hysteresis is not due to the degradation of the material but to a significant increase in the QTM rate, which they confirm by using alternating current (ac) magnetic susceptibility measurements. They conclude that transverse terms of the magnetic anisotropy, which accelerate the QTM rate, are induced by the different crystal packing environments in the amorphous samples.

The relationship between coordination geometry and LF parameters in the Hamiltonian have been extensively studied both experimentally and theoretically [8-16,22-28]. These studies show that $D_{4 d}$ symmetry of the coordination geometry of $\mathrm{Ln}^{\mathrm{III}}$ ions leads to quenching the off-diagonal term, which contributes to transverse anisotropy. Recently, our group has reported that the closer the twist angle between ligands $(\varphi)$ is to $45^{\circ}$, the greater the $U_{\text {eff }}$ value, and this can be adjusted by fine tuning the octa-coordination geometries using a combination of porphyrin and phthalocyanine ligands [29]. This result is consistent with the fact that the contribution of the off-diagonal LF terms is due to the symmetry of the octa-coordination environment.

In addition to the LF parameters, in a recent study, it has been shown that Ln-Ln interactions, so-called f-f interactions, have a large effect on the SMM properties in the solid state [22,30-43]. In Ln SMMs, 4 f electrons, which are responsible for the magnetism, are strongly shielded by the outer shell electrons. Therefore, the exchange interactions via overlap of the $4 \mathrm{f}$ orbits are negligibly small, and the magnetic dipole-dipole (MD) interactions are the dominant intermolecular interactions [32,34]. The MD interactions are known to act as an internal magnetic field [38]. In applied direct current (dc) fields, the energies of the up and down spin states of SMMs become different due to Zeeman splitting. As a result, applied dc fields diminish QTM between ground states, and the relaxation time $(\tau)$ increases. On the other hand, when transverse fields are applied, the ground and excited states mix, inducing QTM [44,45]. Since the magnetic field made by the magnetic moment of SMMs is highly anisotropic, the direction of the easy magnetization between the Ln ions heavily affects the SMM properties. In other words, when the easy axes of the magnetization of two SMMs align collinearly, $\tau$ increases due to the suppression of QTM, and SMM properties improve. In contrast, if the easy axes do not orientate in the same direction, QTM is enhanced, and SMM properties degrade [46].

As mentioned above, the SMM properties are strongly affected by QTM when the environment is different from the crystalline phase. Considering two components of the LF parameters and the MD interactions, we focused on two crystal structures of $\mathrm{TbPc}_{2}[47,48]$ with or without crystal solvent molecules. In this study, we compared the molecular structure and the spin relaxation dynamics, and herein we present an effective molecular design strategy for suppressing QTM via the coordination geometry and the MD interactions. 


\section{Results and Discussion}

\subsection{Comparison of the Crystal Structures of $\mathbf{1}$ and $\mathbf{2}$}

$\mathrm{TbPc}_{2}$ crystallized without any crystal solvent molecules giving $\mathbf{1}$ and with dichloromethane molecules giving 2 as reported previously $[47,48]$ in the orthorhombic space groups $P 2{ }_{1} 2{ }_{1}{ }_{1}$ and $P n m a$, respectively (Figure 1). The average distance between the $\mathrm{Tb}^{\mathrm{III}}$ ions and a coordinated isoindole $\mathrm{N}$ atom $\left(\mathrm{N}_{\text {iso }}\right)$ was determined to be $2.408 \AA$ in $\mathbf{1}$ and $2.418 \AA$ in 2 . The twist angle $(\varphi)$ between the two Pc rings was determined to be $41.37^{\circ}$ in 1 and $44.93^{\circ}$ in $\mathbf{2}$, causing a square antiprism (SAP) coordination geometry and a pseudo four-fold axis $\left(C_{4}\right)$ perpendicular to the Pc rings in both crystal structures. $\mathrm{TbPc}_{2}$ has a magnetic easy axis in same orientation with the $C_{4}$ axis, as shown in Figure 2 with the red arrow. In addition, the angle $(\alpha)$ between the $C_{4}$ axis and the direction of the $\mathrm{Ln}{ }^{\mathrm{III}}-\mathrm{N}_{\text {iso }}$ coordination bond is known to have a strong influence on the LF parameters [22]. It was $54.56^{\circ}$ in 1 and $54.60^{\circ}$ in 2.

(a)

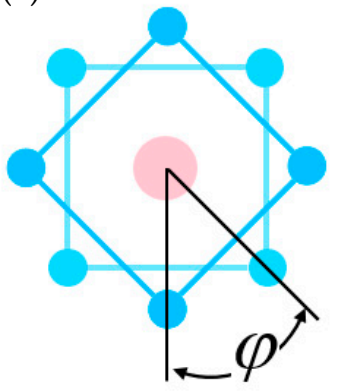

(b)

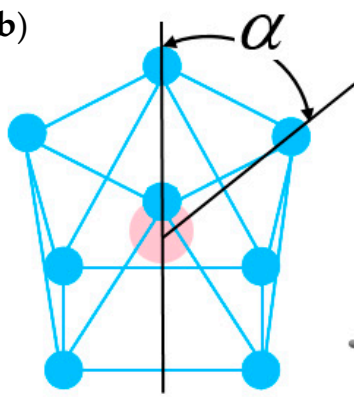

(c)
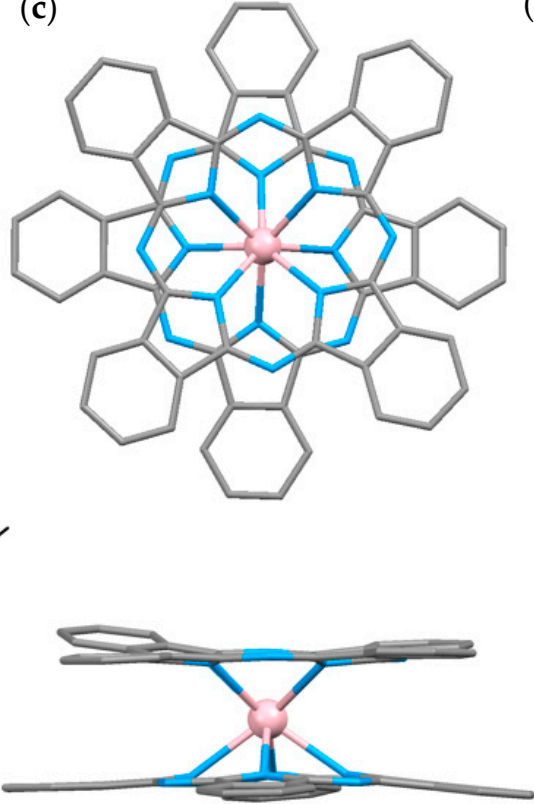

(d)
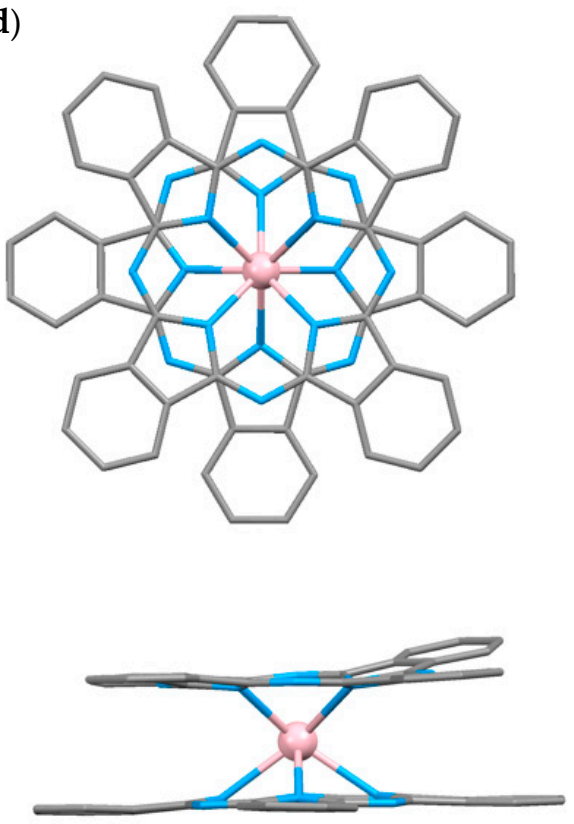

Figure 1. (a) Twist angle in square antiprism (SAP) in $\mathrm{LnPc}_{2} ;(\mathbf{b})$ Schematic illustration of the SAP coordination environment of $\mathrm{LnP}_{2}$. Crystal structures of $\mathbf{1}$ (c) and $\mathbf{2}(\mathbf{d})$. Top view (upper) and side view (lower). Hydrogen atoms were omitted for clarity. (Tb, pink; N, blue; $\mathrm{C}$, gray).

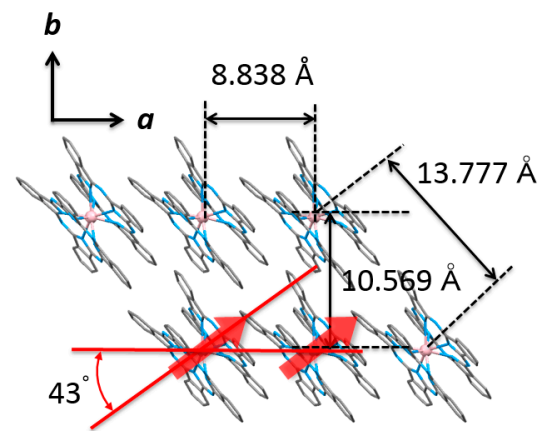

(a)

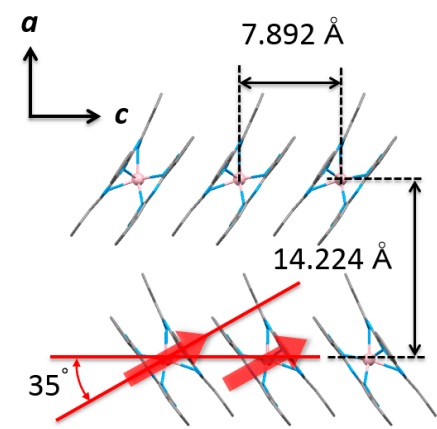

(b)

Figure 2. Molecular packing of $\mathrm{TbPc}_{2}$ (a) for 1 viewed from the $c$ axis, (b) for $\mathbf{2}$ viewed from the $b$ axis. The values in the figure are the intermolecular $\mathrm{Tb}^{\mathrm{III}}-\mathrm{Tb}^{\mathrm{III}}$ distances. Hydrogen atoms were omitted for clarity. 
The LF Hamiltonian can be written as $\hat{H}_{L F}=\sum_{k=2,4,6} \sum_{q=-k}^{k} B_{k}^{q} O_{k}^{q} . B_{k}^{q}$ is LF parameters, where $q$ accounts for the proportionality between the electrostatic potential, $k$ is the order of spherical harmonicity, and $O_{k}^{q}$ are spin operators [22,23]. For ideal $D_{4 \mathrm{~d}} \operatorname{SAP}$ symmetry $\left(\varphi=45^{\circ}\right.$ and $\left.\alpha=54.74^{\circ}\right)$, only three parameters $(k=2,4$, and $6 ; q=0)$ are needed, and these parameters contribute to the axial anisotropy. When coordination geometry is distorted from ideal $D_{4 \mathrm{~d}}$, the off-diagonal terms $\left(B_{4}{ }^{4}, B_{6}{ }^{4}\right)$, which are parameters for the transverse anisotropy, appear in the Hamiltonian. They cause mixing between the ground states of the up and down spins and induce QTM. As describe above, $\varphi$ strongly affects the SMM properties via the LF parameters since the structures deviate from $D_{4 \mathrm{~d}}$ symmetry. In this study, the deviation from $D_{4 \mathrm{~d}}$ symmetry is smaller for $\mathbf{2}$ than it is for $\mathbf{1}$. Therefore, we think that QTM in 2 is effectively suppressed.

$\pi-\pi$ stacking between the intermolecular Pc ligands caused a slipped column structure in both. The strength of the MD interactions is inversely proportional to one third the distance between spin $i$ and $j\left(r_{\mathrm{ij}}\right)$. The nearest $\mathrm{Tb}^{\mathrm{III}}-\mathrm{Tb}^{\mathrm{III}}$ distance was determined to be $8.838 \AA$ in $\mathbf{1}$ and $7.892 \AA$ in $\mathbf{2}$. Moreover, the strength of the dipole interactions depend on the quantity $\left(3 \cos ^{2} \theta-1\right)$, where $\theta$ is angle made by the magnetic easy axis and the line between neighboring $\mathrm{Tb}^{\mathrm{III}}$ ions in the same column. $\theta$ is $43^{\circ}$ in 1 and $35^{\circ}$ in 2 . Because the $\theta$ values are less than $54.7^{\circ}$, the so-called magic angle, we thought that ferromagnetic MD interactions were active in both 1 and 2 [49] and that the MD interactions were stronger in $\mathbf{2}$ than they were in $\mathbf{1}$. Selected crystallographic data for $\mathbf{1}$ and $\mathbf{2}$ are compiled in Table 1.

Table 1. Structural parameters for 1 and 2.

\begin{tabular}{ccc}
\hline & $\mathbf{1}$ & $\mathbf{2}$ \\
\hline average $\mathrm{Tb}-\mathrm{N}_{\text {iso }}$ distance $(\AA)$ & 2.408 & 2.418 \\
$\varphi,\left(^{\circ}\right)$ & 41.37 & 44.93 \\
$\alpha,\left(^{\circ}\right)$ & 54.56 & 54.60 \\
$r_{\mathrm{ij}},(\AA)$ & 8.838 & 7.892 \\
$\theta,\left(^{\circ}\right)$ & 43 & 35 \\
\hline
\end{tabular}

\subsection{Static Magnetic Properties}

To determine the magnetic interactions in each molecular packing, dc magnetic measurements were performed. To eliminate the effects of intermolecular interactions, magnetically diluted crystalline samples were prepared $\left(\mathbf{1}^{\prime}\right)$ by doping $\mathrm{TbPc}_{2}$ into $\mathrm{YPc}_{2}$, of which the crystal is isomorphous with that of $\mathbf{1}$. Both $\mathrm{TbPc}_{2}$ and $\mathrm{YPc}_{2}$ have an unpaired electron delocalized on the Pc ligands [50,51]. Exchange interactions mediated by $\pi$-stacking of $\mathrm{Pc}$ ligands in $\mathrm{YPc}_{2}$ compounds, where MD interactions are negligible compared to $\mathrm{TbPc}_{2}$ have been extensively investigated. Literature reports on the low $T$ behavior of $\mathrm{YPc}_{2}$ indicate that antiferromagnetic interactions are active along the chains of stacked $\mathrm{YPc}_{2}$. In contrast, $\mathrm{YPc}_{2} \cdot \mathrm{CH}_{2} \mathrm{Cl}_{2}$ exhibits ferromagnetic interactions along the stacked chain [51,52]. As shown in Figure $3 \mathrm{a}$, the $\chi_{\mathrm{M}} T$ values for 1 and 2 increased with a decrease in $T$ below $10 \mathrm{~K}$ due to ferromagnetic MD interactions between the $\mathrm{Tb}^{\mathrm{III}}$ ions. The increase is larger for $\mathbf{2}$ than it is for $\mathbf{1}$. This result indicates that the MD interactions in $\mathbf{2}$ are stronger, which is consistent with the conclusions from the crystal structure. In contrast, the $\chi_{\mathrm{M}} T$ value for $\mathbf{1}^{\prime}$ decreased with a decrease in $T$ because of depopulation of the excited states [53,54]. In addition, our observations suggest that exchange interactions in $\mathrm{TbPc}_{2}$ compounds are negligibly small compared to the MD interactions.

In the magnetization $(M)$ versus field $(H)$ curves for $\mathbf{1}, \mathbf{2}$, and $\mathbf{1}^{\prime}$ at $1.82 \mathrm{~K}$, magnetic hysteresis was observed. The area inside the loop increased in order of $\mathbf{1}, \mathbf{1}^{\prime}$, and $\mathbf{2}$. This result shows that the $\mathrm{MD}$ interactions affect the magnetic hysteresis. On the other hand, the magnetic isolation of $\mathrm{TbPc}_{2}$ to minimize the MD interactions also improved the SMM properties, as previously reported for most SMMs [36,55-59]. Therefore, we concluded that the MD interactions in 1 degraded the SMM properties. 


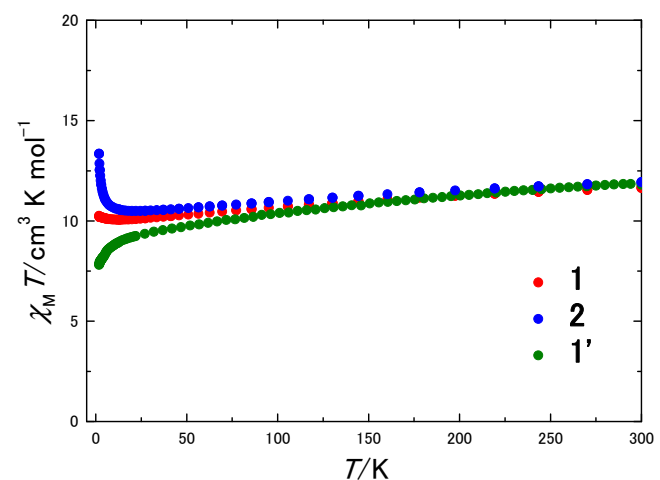

(a)

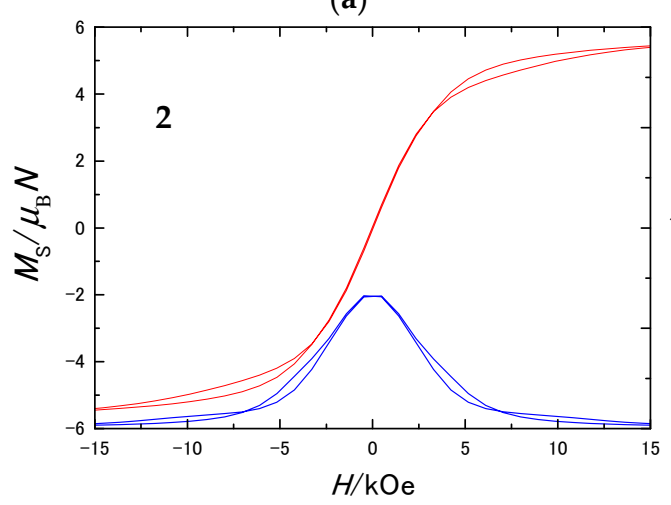

(c)

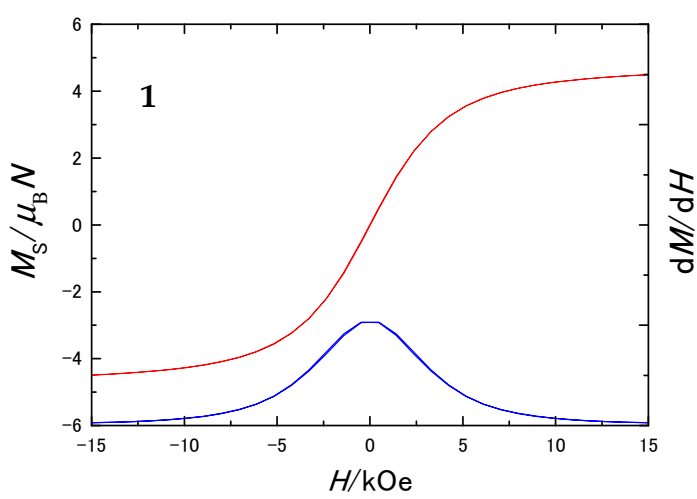

(b)

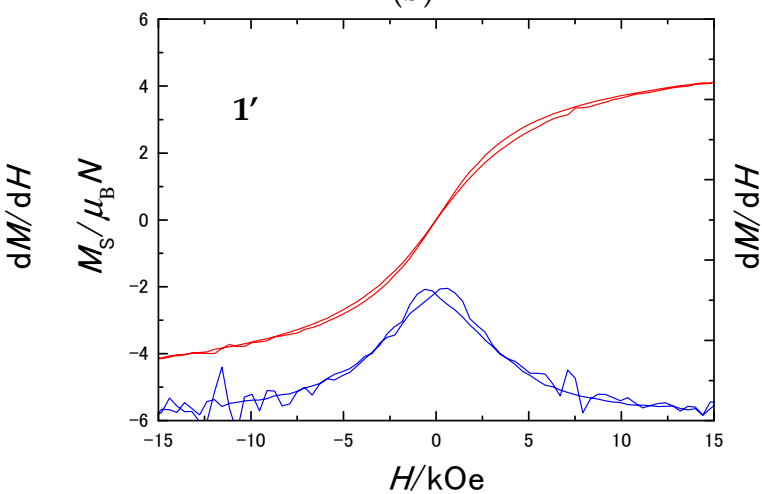

(d)

Figure 3. (a) Direct current (dc) magnetic susceptibility for $\mathbf{1}, \mathbf{2}$, and $\mathbf{1}^{\prime}$. The solid lines are guides for eyes. Magnetization $(M)$ versus field $(H)$ and $\mathrm{d} M / \mathrm{d} H$ versus $H$ for $(\mathbf{b}) \mathbf{1}$; (c) $\mathbf{2}$; and (d) $\mathbf{1}^{\prime}$ at $1.82 \mathrm{~K}$. Average field sweep rate was $25 \mathrm{Oe} \mathrm{s}^{-1}$.

\subsection{Dynamic Magnetic Properties}

To investigate the magnetic relaxation process, ac magnetic measurements were performed on $\mathbf{1}$ and 2 with and without an applied external magnetic field $\left(H_{\mathrm{dc}}\right) . \tau$ was obtained by simultaneously fitting the real $\left(\chi_{\mathrm{M}^{\prime}}\right)$ and imaginary $\left(\chi_{\mathrm{M}^{\prime \prime}}\right)$ parts of the ac magnetic susceptibility with the generalized Debye model (Equations (S1) and (S2)) [60]. The peaks in $\chi_{\mathrm{M}}$ " plot for 2 were observed in a lower frequency $(v)$ region than they were for 1 , meaning that $\tau$ was slower for 2 . As seen in Figure $4 \mathrm{~b}$, the plot is divided into two parts. In the high- $T$ region, where $\tau$ depends on $T$, the Orbach process is dominant [61]. $U_{\text {eff }}$ and frequency factor $\left(\tau_{0}\right)$ were determined by fitting the data in the high- $T$ region using the Arrhenius equation (Equation (S6)) $\left(1 ; U_{\text {eff }}=523 \mathrm{~cm}^{-1}, \tau_{0}=7.7 \times 10^{-12} \mathrm{~s}, 2 ; U_{\text {eff }}=556 \mathrm{~cm}^{-1}\right.$, $\tau_{0}=2.2 \times 10^{-10} \mathrm{~s}$ ). Although in the low- $T$ region, we tried to fit $\tau$ for $\mathbf{1}$, which still has some dependence on $T$, by using combinations of direct, Raman, and QTM relaxation processes, the data could not be correctly fit (Figure S7 direct + QTM, Figure S8 Raman + QTM, Figure S9 direct + Raman + QTM). We think that intermolecular interactions affect the spin ground state as a perturbation and induce complex mixing of the relaxation process. We could fit the data points for $\mathbf{1}$ in the low- $T$ region by considering the Orbach process and QTM $\left(U_{\text {eff }}=3.92 \mathrm{~cm}^{-1}, \tau_{0}=3.3 \times 10^{-4} \mathrm{~s}, \tau_{\mathrm{QTM}}=7.84 \times 10^{-4} \mathrm{~s}\right)$ (Figure S10), supporting that relaxation occurs through a complex mixture of processes in the low- $T$ region. One $\mathrm{TbPc}_{2}$ molecule does not have such an excited spin state $U_{\text {eff }}=3.92 \mathrm{~cm}^{-1}$ for the Orbach process, whereas in the crystal structure, intermolecular magnetic interactions can split the ground state as reported for the Tb triple-decker complex [37]. On the other hand, $\tau$ for 2, which scarcely depends on $T$, was fitted by considering QTM $\left(\tau_{\mathrm{QTM}}=3.51 \times 10^{-2} \mathrm{~s}\right)$ (Figure S11). $U_{\text {eff }}$ values for $\mathbf{1}$ and $\mathbf{2}$ in the high-T region were found to be similar. However, the $\tau$ values were different in the low-T region. 


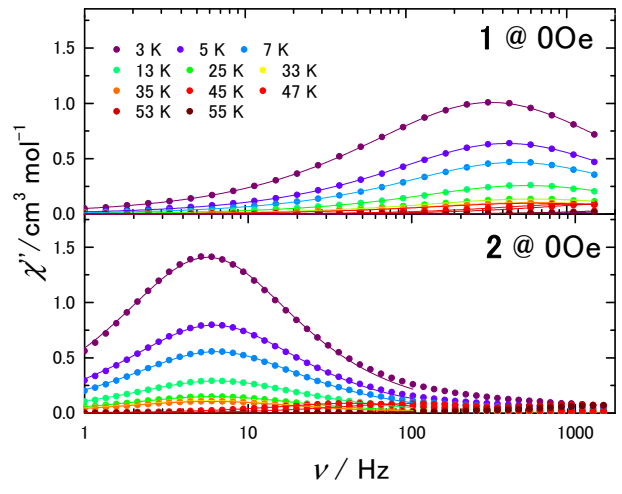

(a)

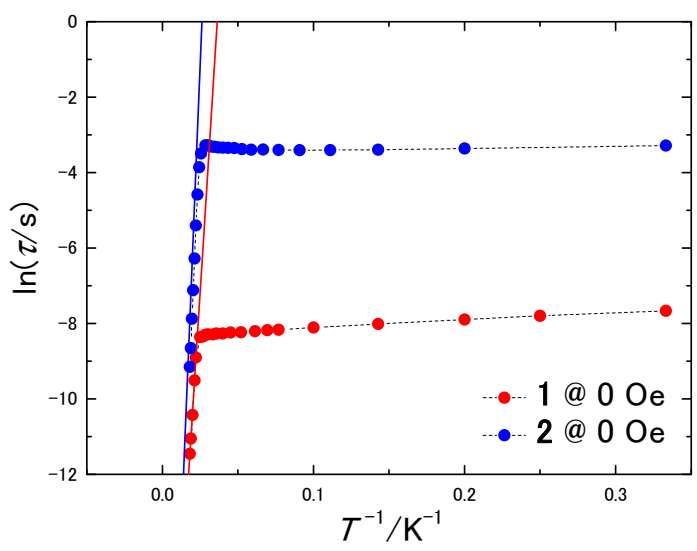

(b)

Figure 4. (a) $\chi_{\mathrm{M}}{ }^{\prime \prime}$ vs. $v$ plot for 1 and 2 in a zero field. The solid lines were fitted by using the generalized Debye model; (b) Arrhenius plots for $\mathbf{1}$ and 2. The solid lines were fitted by using the Arrhenius equation. The dashed lines are guides for eyes.

In an $H_{\mathrm{dc}}$ of 3000 Oe, the peak in $\chi_{\mathrm{M}}$ " plot for 1 clearly shifted toward the low $v$ region, as shown in Figure 5a. Arrhenius plot for 1 in $H_{\mathrm{dc}}$ of 3000 Oe (Figure 5b) was fitted by using the Arrhenius equation for high- $T$ region $\left(U_{\text {eff }}=512 \mathrm{~cm}^{-1}, \tau_{0}=5.3 \times 10^{-12} \mathrm{~s}\right)$ and a combination of the Orbach process and QTM for the low- $T$ region $\left(U_{\text {eff }}=9.61 \mathrm{~cm}^{-1}, \tau_{0}=4.2 \times 10^{-2} \mathrm{~s}, \tau_{\mathrm{QTM}}=8.83 \times 10^{-2} \mathrm{~s}\right)$ (Figure S12). The $H_{\mathrm{dc}}$ did not affect $U_{\text {eff }}$ for the high- $T$ region. On the other hand, $H_{\mathrm{dc}}$ caused $\tau$ to be three orders of magnitude longer than it was in an $H_{\mathrm{dc}}$ of 0 Oe. Since the $H_{\mathrm{dc}}$ induce Zeeman splitting, which causes a difference in the energies of the spin states, the QTM rate between ground states was slower, and $\tau$ increased.

These results show that the molecular packing in 2 effectively suppresses QTM via the small contributions of the off-diagonal terms in the LF Hamiltonian and the relatively strong MD interactions. On the other hand, although ferromagnetic MD interactions were active in 1, the $\tau$ values in low- $T$ region were similar to those for $\mathbf{1}^{\prime}\left(\tau \approx 10^{-4} \mathrm{~s}\right)$. This indicates that the MD interactions in $\mathbf{1}$ do not suppress QTM. We believe that this is because of the large $\theta$ value mentioned in crystal structure section. Moreover, from the results of dc and ac magnetic measurements, not only the off-diagonal terms but also the collinearity of the MD interactions strongly affect QTM.
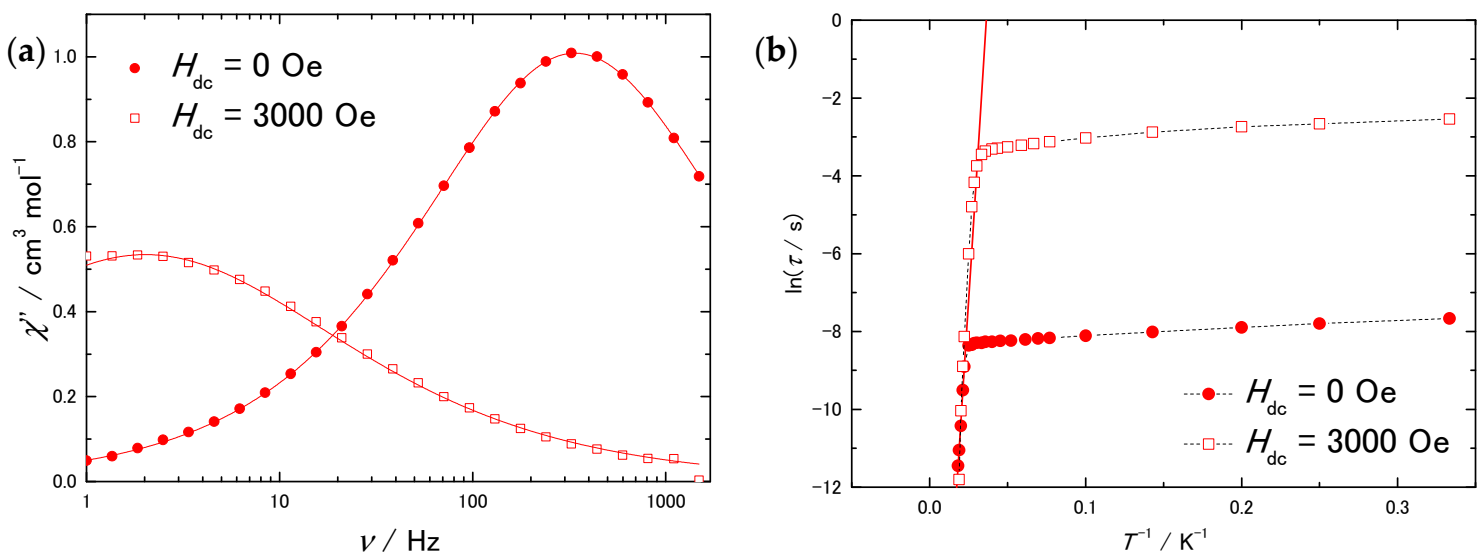

Figure 5. (a) $\chi_{\mathrm{M}}{ }^{\prime \prime}$ vs. $v$ plot for 1 in $H_{\mathrm{dc}}$ of 0 Oe and 3000 Oe at $3 \mathrm{~K}$. The solid lines were fitted by using the generalized Debye model. (b) Arrhenius plots for 1 in $H_{\mathrm{dc}}$ of 0 Oe and 3000 Oe. The solid lines were fitted by using the Arrhenius equation. The dashed lines are guides for eyes. 


\section{Materials and Methods}

\subsection{Preparation of $\mathrm{TbP}_{2}(\mathbf{1})$ and $\mathrm{TbP}_{2} \cdot \mathrm{CH}_{2} \mathrm{Cl}_{2}$ (2)}

$\mathrm{TbPc}_{2}$ was synthesized following a reported procedure $[47,48]$. The obtained powder sample was recrystallized from $\mathrm{CHCl}_{3} / \mathrm{MeOH}$, which afforded deep green needle-like crystals of $\mathbf{1}$, and recrystallized from $\mathrm{CH}_{2} \mathrm{Cl}_{2}$ /Hexane, which afforded deep green needle-like crystals of 2 .

\subsection{Preparation of Magnetically Diluted Sample (1')}

$\mathrm{TbPc}_{2} 5.69 \mathrm{mg}(4.04 \mathrm{mmol})$ and $\mathrm{YPc}_{2} 49.54 \mathrm{mg}(37.01 \mathrm{mmol})$ were mixed in $10 \mathrm{~mL}$ of $\mathrm{CHCl}_{3}$ by using ultrasonication (Bransonic ${ }^{\circledR}$ ultrasonic cleaner 2510MT, Bransonic Ultrasonics Corporation, Danbury, CT, USA) for $1 \mathrm{~h}$. Addition of an excess amount of hexane afforded a powder sample of diluted $\mathrm{TbPc}_{2}\left(\mathbf{1}^{\prime}\right)$.

\subsection{Physical Property Measurements}

Powder X-ray diffraction (PXRD) measurements were performed on crushed polycrystalline samples by using an AFC-7R/ LW (Rigaku, Akishima, Japan) operated at $50 \mathrm{kV}$ and $300 \mathrm{~mA}$ at $293 \mathrm{~K}$ (Figure S1). The data were collected in the diffraction angle range of $3-60^{\circ}$ in steps of $0.02^{\circ}$ every $2 \mathrm{~s}$. To prevent the crystal solvent from evaporating, the samples were loaded into a capillary (diameter: $0.8 \mathrm{~mm}$, length: $80 \mathrm{~mm}$, Hilgenderg GmbH, Malsfeld, Germany) with the mother liquor. PXRD patterns were simulated from the single-crystal data by using Mercury 3.0 (The Cambridge Crystallographic Data Centre, Cambridge, UK).

Magnetic susceptibility measurements were performed by using Quantum Design SQUID magnetometer (MPMS-XL and MPMS-3, Quantum Design, Inc., San Diego, CA, USA). Direct current measurements were performed in the $T$ range of $1.8-300 \mathrm{~K}$ in dc magnetic fields $\left(H_{\mathrm{dc}}\right)$ of -70.000 to 70,000 Oe. Alternating current measurements were performed in the frequency $(v)$ range of $1-1488 \mathrm{~Hz}$ in an $H_{\mathrm{ac}}$ of $3 \mathrm{Oe}$ in the presence of an $H_{\mathrm{dc}}$ (zero and $3000 \mathrm{Oe}$ ). Measurements were performed on randomly oriented powder samples of $\mathbf{1}$ and $\mathbf{2}$, which were placed in gel capsules and fixed with $n$-eicosane to prevent them from moving during measurements. All data were corrected for $n$-eicosane and diamagnetic contribution from the molecules by using Pascal's constants.

\section{Conclusions}

In this work, we synthesized two different crystals of a terbium(III)-phthalocyaninato double-decker complex (1: $\mathrm{TbPc}_{2}, 2$ : $\left.\mathrm{TbPc}_{2} \cdot \mathrm{CH}_{2} \mathrm{Cl}_{2}\right)$ and investigated the relationship between molecular packing and magnetic properties. From crystal structure analysis, the $\varphi$ value near $45^{\circ}$ for 2 corresponded to a small contribution of the off-diagonal terms in the LF Hamiltonian. In addition, the nearest $\mathrm{Tb}^{\mathrm{III}}-\mathrm{Tb}^{\mathrm{III}}$ distance is shorter, and the $\mathrm{TbPc}_{2}$ molecules packed with a small $\theta$ for $\mathbf{2}$, suggesting that MD interactions are stronger in $\mathbf{2}$ than they are in $\mathbf{1}$. This is consistent with the results obtained from dc magnetic measurements. $\tau$ of $\mathbf{2}$ exhibited similar behavior with that of $\mathbf{1}$ in an $H_{\mathrm{dc}}$ of $3000 \mathrm{Oe}$, and they were relatively slow. These results suggest that the molecular packing in 2 is suitable for suppressing QTM. In contrast, although ferromagnetic MD interactions are active in 1, the $\tau$ values were similar to those of $\mathbf{1}^{\prime}$ where no magnetic interactions occur. From these results, we concluded that the collinearity of the MD interactions was important for suppressing QTM. We believe that we can increase $\tau$ by properly tuning the three parameters $\varphi, r_{\mathrm{ij}}, \theta$, and this idea can be applied to the design of SMMs with slow $\tau$.

Supplementary Materials: Supplementary materials are available online.

Acknowledgments: This work was financially supported by a Grant-in-Aid for Scientific Research (20225003) and Grant-in-Aid for Young Scientists (24750119), Scientific Research (15K05467) from the Ministry of Education, Culture, Sports, Science, and Technology (MEXT) and CREST (JPMJCR12L3), JST, Japan. 
Author Contributions: K.K. and M.Y. conceived and designed the experiment; T.Y. and K.K. performed the experiments; T.Y. and K.K analyzed the data; T.Y. and B.K.B. wrote the paper.

Conflicts of Interest: The authors declare no conflict of interest. The funding sponsors had no role in the design of the study; in the collection, analyses, and interpretation of data, in the writing of the manuscript, or in the decision to publish the results.

\section{References}

1. Sessoli, R.; Gatteschi, D.; Caneschi, A.; Novak, M.A. Magnetic bistability in a metal-ion cluster. Nature 1993, 365, 141-143. [CrossRef]

2. Woodruff, D.N.; Winpenny, R.E.; Layfield, R.A. Lanthanide single-molecule magnets. Chem. Rev. 2013, 113, 5110-5148. [CrossRef] [PubMed]

3. Thomas, L.; Lionti, F.; Ballou, R.; Gattechi, D.; Sessoli, R.; Barbara, B. Macroscopic quantum tunneling of magnetization in a single crystal of nanomagnets. Nature 1996, 383, 145-147. [CrossRef]

4. Gatteschi, D.; Sessoli, R. Quantum Tunneling of Magnetization and Related Phenomena in Molecular Materials. Angew. Chem. Int. Ed. 2003, 42, 268-297. [CrossRef] [PubMed]

5. Friedman, J.R.; Sarachik, M.P.; Tejada, J.; Ziolo, R. Macroscopic Measurement of Resonant Magnetization Tunneling in High-Spin Molecules. Phys. Rev. Lett. 1996, 76, 3830-3833. [CrossRef] [PubMed]

6. Rinehart, J.D.; Fang, M.; Evans, W.J.; Long, J.R. A N ${ }^{3-}$ radical-bridged terbium complex exhibiting magnetic hysteresis at 14 K. J. Am. Chem. Soc. 2011, 133, 14236-14239. [CrossRef] [PubMed]

7. Rinehart, J.D.; Fang, M.; Evans, W.J.; Long, J.R. Strong exchange and magnetic blocking in $\mathrm{N}_{2}{ }^{3-}$ radical-bridged lanthanide complexes. Nat. Chem. 2011, 3, 538-542. [CrossRef] [PubMed]

8. Ishikawa, N.; Sugita, M.; Ishikawa, T.; Koshihara, S.; Kaizu, Y. Lanthanide Double-Decker Complexes Functioning as Magnets at the Single-Molecular Level. J. Am. Chem. Soc. 2003, 125, 8694-8695. [CrossRef] [PubMed]

9. Ishikawa, N. Single molecule magnet with single lanthanide ion. Polyhedron 2007, 26, 2147-2153. [CrossRef]

10. Ishikawa, N.; Sugita, M.; Wernsdorfer, W. Quantum Tunneling of Magnetization in Lanthanide Single-Molecule Magnets: Bis(phthalocyaninato)terbium and Bis(phthalocyaninato)dysprosium Anions. Angew. Chem. Int. Ed. 2005, 44, 2931-2935. [CrossRef] [PubMed]

11. Ishikawa, N.; Sugita, M.; Ishikawa, T.; Koshihara, S.; Kaizu, Y. Mononuclear Lanthanide Complexes with a Long Magnetization Relaxation Time at High Temperatures: A New Category of Magnets at the Single-Molecular Level. J. Phys. Chem. B 2004, 108, 11265-11271. [CrossRef]

12. Takamatsu, S.; Ishikawa, N. A theoretical study of a drastic structural change of bis(phthalocyaninato)lanthanide by ligand oxidation: Towards control of ligand field strength and magnetism of single-lanthanide-ionic single molecule magnet. Polyhedron 2007, 26, 1859-1862. [CrossRef]

13. Ishikawa, N.; Miki Sugita, M.; Okubo, T.; Tanaka, N.; Iino, T.; Kaizu, Y. Determination of Ligand-Field Parameters and f-Electronic Structures of Double-Decker Bis(phthalocyaninato)lanthanide Complexes. Inorg. Chem. 2003, 42, 2440-2446. [CrossRef] [PubMed]

14. Ishikawa, N. Simultaneous Determination of Ligand-Field Parameters of Isostructural Lanthanide Complexes by Multidimensional Optimization. J. Phys. Chem. A 2003, 107, 5831-5835. [CrossRef]

15. Ishikawa, N.; Kaizu, Y. Synthetic, spectroscopic and theoretical study of novel supramolecular structures composed of lanthanide phthalocyanine double-decker complexes. Coord. Chem. Rev. 2002, 226, 93-101. [CrossRef]

16. Takamatsu, S.; Ishikawa, T.; Koshihara, S.; Ishikawa, N. Significant Increase of the Barrier Energy for Magnetization Reversal of a Single-4f-Ionic Single-Molecule Magnet by a Longitudinal Contraction of the Coordination Space. Inorg. Chem. 2007, 46, 7250-7252. [CrossRef] [PubMed]

17. Vincent, R.; Klyatskaya, S.; Ruben, M.; Wernsdorfer, W.; Balestro, F. Electronic read-out of a single nuclear spin using a molecular spin transistor. Nature 2012, 488, 357-360. [CrossRef] [PubMed]

18. Urdampilleta, M.; Klyatskaya, S.; Cleuziou, J.P.; Ruben, M.; Wernsdorfer, W. Supramolecular spin valves. Nat. Mater. 2011, 10, 502-506. [CrossRef] [PubMed]

19. Urdampilleta, M.; Nguyen, N.V.; Cleuziou, J.P.; Klyatskaya, S.; Ruben, M.; Wernsdorfer, W. Molecular quantum spintronics: Supramolecular spin valves based on single-molecule magnets and carbon nanotubes. Int. J. Mol. Sci. 2011, 12, 6656-6667. [CrossRef] [PubMed] 
20. Thiele, S.; Balestro, F.; Ballou, R.; Klyatskaya, S.; Ruben, M.; Wernsdorfer, W. Electrically driven nuclear spin resonance in single-molecule magnets. Science 2014, 344, 1135-1138. [CrossRef] [PubMed]

21. Malavolti, L.; Mannini, M.; Car, P.-E.; Campo, G.; Pineider, F.; Sessoli, R. Erratic magnetic hysteresis of $\mathrm{TbPc}_{2}$ molecular nanomagnets. J. Mater. Chem. C 2013, 1, 2935-2942. [CrossRef]

22. Sakaue, S.; Fuyuhiro, A.; Fukuda, T.; Ishikawa, N. Dinuclear single-molecule magnets with porphyrin-phthalocyanine mixed triple-decker ligand systems giving SAP and SP coordination polyhedra. Chem. Commun. 2012, 48, 5337-5339. [CrossRef] [PubMed]

23. Sorace, L.; Benelli, C.; Gatteschi, D. Lanthanides in molecular magnetism: Old tools in a new field. Chem. Soc. Rev. 2011, 40, 3092-3104. [CrossRef] [PubMed]

24. Liddle, S.T.; van Slageren, J. Improving f-element single molecule magnets. Chem. Soc. Rev. 2015, 44, 6655-6669. [CrossRef] [PubMed]

25. Perfetti, M.; Lucaccini, E.; Sorace, L.; Costes, J.P.; Sessoli, R. Determination of magnetic anisotropy in the LnTRENSAL complexes ( $\mathrm{Ln}=\mathrm{Tb}, \mathrm{Dy}, \mathrm{Er})$ by torque magnetometry. Inorg. Chem. 2015, 54, 3090-3092. [CrossRef] [PubMed]

26. Pedersen, K.S.; Ungur, L.; Sigrist, M.; Sundt, A.; Schau-Magnussen, M.; Vieru, V.; Mutka, H.; Rols, S.; Weihe, H.; Waldmann, O.; et al. Modifying the properties of $4 \mathrm{f}$ single-ion magnets by peripheral ligand functionalisation. Chem. Sci. 2014, 5, 1650-1660. [CrossRef]

27. Rinehart, J.D.; Long, J.R. Exploiting single-ion anisotropy in the design of f-element single-molecule magnets. Chem. Sci. 2011, 2, 2078-2085. [CrossRef]

28. Baldovi, J.J.; Cardona-Serra, S.; Clemente-Juan, J.M.; Coronado, E.; Gaita-Arino, A.; Palii, A. Rational design of single-ion magnets and spin qubits based on mononuclear lanthanoid complexes. Inorg. Chem. 2012, 51, 12565-12574. [CrossRef] [PubMed]

29. Katoh, K.; Breedlove, B.K.; Yamashita, M. Symmetry of octa-coordination environment has a substantial influence on dinuclear $\mathrm{Tb}^{\mathrm{III}}$ triple-decker single-molecule magnets. Chem. Sci. 2016, 7, 4329-4340. [CrossRef]

30. Ishikawa, N.; Iino, T.; Kaizu, Y. Determination of Ligand-Field Parameters and f-Electronic Structures of Hetero-Dinuclear Phthalocyanine Complexes with a Diamagnetic Yttrium(III) and a Paramagnetic Trivalent Lanthanide Ion. J. Phys. Chem. A 2002, 106, 9543-9550. [CrossRef]

31. Ishikawa, N.; Iino, T.; Kaizu, Y. Study of ${ }^{1} \mathrm{H}-\mathrm{NMR}$ Spectra of Dinuclear Complexes of Heavy Lanthanides with Phthalocyanines Based on Separation of the Effects of Two Paramagnetic Centers. J. Phys. Chem. A 2003, 107, 7879-7884. [CrossRef]

32. Ishikawa, N.; Iino, T.; Kaizu, Y. Interaction between f-Electronic Systems in Dinuclear Lanthanide Complexes with Phthalocyanines. J. Am. Chem. Soc. 2002, 124, 11440-11447. [CrossRef] [PubMed]

33. Ishikawa, N.; Otsuka, S.; Kaizu, Y. The effect of the f-f interaction on the dynamic magnetism of a coupled $4 \mathrm{f}^{8}$ system in a dinuclear terbium complex with phthalocyanines. Angew. Chem. Int. Ed. 2005, 44, 731-733. [CrossRef] [PubMed]

34. Fukuda, T.; Kuroda, W.; Ishikawa, N. Observation of long-range f-f interactions between two f-electronic systems in quadruple-decker phthalocyanines. Chem. Commun. 2011, 47, 11686-11688. [CrossRef] [PubMed]

35. Wang, H.; Liu, T.; Wang, K.; Duan, C.; Jiang, J. Tetrakis(phthalocyaninato) rare-earth-cadmium-rare-earth quadruple-decker sandwich SMMs: Suppression of QTM by long-distance f-f interactions. Chem. Eur. J. 2012, 18, 7691-7694. [CrossRef] [PubMed]

36. Fukuda, T.; Matsumura, K.; Ishikawa, N. Influence of intramolecular f-f interactions on nuclear spin driven quantum tunneling of magnetizations in quadruple-decker phthalocyanine complexes containing two terbium or dysprosium magnetic centers. J. Phys. Chem. A 2013, 117, 10447-10454. [CrossRef] [PubMed]

37. Katoh, K.; Kajiwara, T.; Nakano, M.; Nakazawa, Y.; Wernsdorfer, W.; Ishikawa, N.; Breedlove, B.K.; Yamashita, M. Magnetic relaxation of single-molecule magnets in an external magnetic field: An ising dimer of a terbium(III)-phthalocyaninate triple-decker complex. Chem. Eur. J. 2011, 17, 117-122. [CrossRef] [PubMed]

38. Katoh, K.; Horii, Y.; Yasuda, N.; Wernsdorfer, W.; Toriumi, K.; Breedlove, B.K.; Yamashita, M. Multiple-decker phthalocyaninato dinuclear lanthanoid(III) single-molecule magnets with dual-magnetic relaxation processes. Dalton Trans. 2012, 41, 13582-13600. [CrossRef] [PubMed]

39. Katoh, K.; Isshiki, H.; Komeda, T.; Yamashita, M. Multiple-decker phthalocyaninato Tb(III) single-molecule magnets and Y(III) complexes for next generation devices. Coord. Chem. Rev. 2011, 255, 2124-2148. [CrossRef] 
40. Katoh, K.; Umetsu, K.; Breedlove Brian, K.; Yamashita, M. Magnetic relaxation behavior of a spatially closed dysprosium(III) phthalocyaninato double-decker complex. Sci. China Chem. 2012, 55, 918-925. [CrossRef]

41. Morita, T.; Katoh, K.; Breedlove, B.K.; Yamashita, M. Controlling the dipole-dipole interactions between terbium(III) phthalocyaninato triple-decker moieties through spatial control using a fused phthalocyaninato ligand. Inorg. Chem. 2013, 52, 13555-13561. [CrossRef] [PubMed]

42. Horii, Y.; Katoh, K.; Yasuda, N.; Breedlove, B.K.; Yamashita, M. Effects of f-f interactions on the single-molecule magnet properties of terbium(III)-phthalocyaninato quintuple-decker complexes. Inorg. Chem. 2015, 54, 3297-3305. [CrossRef] [PubMed]

43. Horii, Y.; Katoh, K.; Cosquer, G.; Breedlove, B.K.; Yamashita, M. Weak DyIII-DyIII Interactions in DyIII-Phthalocyaninato Multiple-Decker Single-Molecule Magnets Effectively Suppress Magnetic Relaxation. Inorg. Chem. 2016, 55, 11782-11790. [CrossRef] [PubMed]

44. Wernsdorfer, W.; Bhaduri, S.; Boskovic, C.; Christou, G.; Hendrickson, D.N. Spin-parity dependent tunneling of magnetization in single-molecule magnets. Phys. Rev. B 2002, 65, 180403. [CrossRef]

45. Urdampilleta, M.; Klyatskaya, S.; Ruben, M.; Wernsdorfer, W. Landau-Zener tunneling of a single $\mathrm{Tb}^{3+}$ magnetic moment allowing the electronic read-out of a nuclear spin. Phys. Rev. B 2013, 87, 195412. [CrossRef]

46. Moreno Pineda, E.; Chilton, N.F.; Marx, R.; Dorfel, M.; Sells, D.O.; Neugebauer, P.; Jiang, S.D.; Collison, D.; van Slageren, J.; McInnes, E.J.; et al. Direct measurement of dysprosium(III) . . dysprosium(III) interactions in a single-molecule magnet. Nat. Commun. 2014, 5, 5243. [CrossRef] [PubMed]

47. Cian, A.D.; Moussavi, M.; Fischer, J.; Wens, R. Synthesis, Structure, and Spectroscopic and Magnetic Properties of Lutetium(III) Phthalocyanine Derivatives: $\mathrm{LuPc}_{2} \cdot \mathrm{CH}_{2} \mathrm{Cl}_{2}$ and [LuPc $\left.\left.(\mathrm{OAc})\left(\mathrm{H}_{2} \mathrm{O}\right)_{2}\right)\right] \cdot \mathrm{H}_{2} \mathrm{O} \cdot 2 \mathrm{CH}_{3} \mathrm{OH}$. Inorg. Chem. 1985, 24, 3162-3167. [CrossRef]

48. Katoh, K.; Yoshida, Y.; Yamashita, M.; Miyasaka, H.; Breedlove, B.K.; Kajiwara, T.; Takaishi, S.; Ishikawa, N.; Isshiki, H.; Zhang, Y.F.; et al. Direct Observation of Lanthanide(III)-Phthalocyanine Molecules on Au(111) by Using Scanning Tunneling Microscopy and Scanning Tunneling Spectroscopy and Thin-Film Field-Effect Transistor Properties of Tb(III)- and Dy(III)-Phthalocyanine Molecules. J. Am. Chem. Soc. 2009, 131, 9967-9976. [CrossRef] [PubMed]

49. Damjanovic, M.; Katoh, K.; Yamashita, M.; Enders, M. Combined NMR analysis of huge residual dipolar couplings and pseudocontact shifts in terbium(III)-phthalocyaninato single molecule magnets. J. Am. Chem. Soc. 2013, 135, 14349-14358. [CrossRef] [PubMed]

50. Ishikawa, N.; Sugita, M.; Tanaka, N.; Ishikawa, T.; Koshihara, S.; Kaizu, Y. Upward Temperature Shift of the Intrinsic Phase Lag of the Magnetization of Bis(phthalocyaninato)terbium by Ligand Oxidation Creating an $S=1 / 2$ Spin. Inorg. Chem. 2004, 43, 5498-5500. [CrossRef] [PubMed]

51. Paillaud, J.L.; Drillon, M.; De Cian, A.; Fischer, J.; Weiss, R.; Villeneuve, G. Radical-based ferromagnetic chain in yttrium diphthalocyanine. Phys. Rev. Lett. 1991, 67, 244-247. [CrossRef] [PubMed]

52. Branzoli, F.; Carretta, P.; Filibian, M.; Klyatskaya, S.; Ruben, M. Low-energy spin dynamics in the [YPc $]^{0}$ $S=\frac{1}{2}$ antiferromagnetic chain. Phys. Rev. B 2011, 83, 174419. [CrossRef]

53. Shi, P.F.; Xiong, G.; Zhao, B.; Zhang, Z.Y.; Cheng, P. Anion-induced changes of structure interpenetration and magnetic properties in 3D Dy-Cu metal-organic frameworks. Chem. Commun. 2013, 49, 2338-2340. [CrossRef] [PubMed]

54. Zou, L.; Zhao, L.; Chen, P.; Guo, Y.N.; Guo, Y.; Li, Y.H.; Tang, J. Phenoxido and alkoxido-bridged dinuclear dysprosium complexes showing single-molecule magnet behaviour. Dalton Trans. 2012, 41, 2966-2971. [CrossRef] [PubMed]

55. Cosquer, G.; Pointillart, F.; Golhen, S.; Cador, O.; Ouahab, L. Slow magnetic relaxation in condensed versus dispersed dysprosium(III) mononuclear complexes. Chem. Eur. J. 2013, 19, 7895-7903. [CrossRef] [PubMed]

56. Bi, Y.; Guo, Y.N.; Zhao, L.; Guo, Y.; Lin, S.Y.; Jiang, S.D.; Tang, J.; Wang, B.W.; Gao, S. Capping ligand perturbed slow magnetic relaxation in dysprosium single-ion magnets. Chem. Eur. J. 2011, 17, 12476-12481. [CrossRef] [PubMed]

57. Na, B.; Zhang, X.J.; Shi, W.; Zhang, Y.Q.; Wang, B.W.; Gao, C.; Gao, S.; Cheng, P. Six-coordinate lanthanide complexes: Slow relaxation of magnetization in the dysprosium(III) complex. Chem. Eur. J. 2014, 20, 15975-15980. [CrossRef] [PubMed] 
58. Meihaus, K.R.; Rinehart, J.D.; Long, J.R. Dilution-induced slow magnetic relaxation and anomalous hysteresis in trigonal prismatic dysprosium(III) and uranium(III) complexes. Inorg. Chem. 2011, 50, 8484-8489. [CrossRef] [PubMed]

59. Habib, F.; Lin, P.H.; Long, J.; Korobkov, I.; Wernsdorfer, W.; Murugesu, M. The use of magnetic dilution to elucidate the slow magnetic relaxation effects of a Dy2 single-molecule magnet. J. Am. Chem. Soc. 2011, 133, 8830-8833. [CrossRef] [PubMed]

60. Cole, K.S.; Cole, R.H. Dispersion and Absorption in Dielectrics I. Alternating Current Characteristics. J. Chem. Phys. 1941, 9, 341-351. [CrossRef]

61. Gomez-Coca, S.; Urtizberea, A.; Cremades, E.; Alonso, P.J.; Camon, A.; Ruiz, E.; Luis, F. Origin of slow magnetic relaxation in Kramers ions with non-uniaxial anisotropy. Nat. Commun. 2014, 5, 4300. [CrossRef] [PubMed]

Sample Availability: Not available.

(C) 2017 by the authors. Licensee MDPI, Basel, Switzerland. This article is an open access article distributed under the terms and conditions of the Creative Commons Attribution (CC BY) license (http://creativecommons.org/licenses/by/4.0/). 